\title{
Marcial y los griegos: una «visión del otro» diferente de la de Juvenal
}

\author{
Rosario Cortés Tovar \\ Universidad de Salamanca \\ rocor@usal.es

\begin{abstract}
Martial and the Greeks: A 'View of the Other'
Different from Juvenal's
\end{abstract}

\begin{abstract}
La visión de los griegos como «los otros» en Marcial, frente a lo que normalmente se piensa, no comparte la xenofobia expresada por Juvenal en III 58-125, sino que es mucho más compleja. La razón se encuentra, sobre todo, en que, mientras el punto de vista de Juvenal con respecto a los griegos es el de un nacionalista estrecho nacido en el corazón del Imperio, el de Marcial es el de un ciudadano romano nacido en la periferia para quien la romanitas se identifica con el Imperio, universal y multicultural. Por eso para él carece de sentido el nacionalismo etnocéntrico impulsor de la visión despreciativa del «otro»; y en consecuencia la helenofobia tiene poca presencia en su obra, además de estar limitada a pequeños ataques chistosos contra individuos particulares, sin que alcance como Juvenal a la graeca natio en su conjunto.
\end{abstract}

Palabras clave: Visión del «otro»; nacionalismo; imperio; Marcial y Juvenal.
Unlike what is usually thought, Martial's view of the Greeks as 'the others' does not share the xenophobia expressed by Juvenal in III $58-125$, but is rather much more complex. The reason for this can be found, above all, in that whereas Juvenal's point of view with respect to the Greeks is one of a strict nationalist born in the heart of the Empire, Martial's perspective is that of a Roman citizen born on the periphery, for whom romanitas is identified with a universal and multicultural Empire. Thus for him an ethnocentric nationalism that fosters a scornful view of the 'other' has no meaning, and therefore Hellenophobia has a negligible presence in his work: it is limited to small flippant attacks on specific individuals, never encompassing the graeca natio as a whole like Juvenal.

Key words: View of the 'other'; nationalism; empire; Martial and Juvenal.

Es de sobra conocido el ataque que Juvenal lanza contra los griegos en III 58-125 y su carácter paradigmático, ya que este texto, además de reunir todos los rasgos característicos de la «visión del otro» como despreciable y amenazador, representa muy bien la tendencia nacionalista y xenófoba de la poesía satírica (Knight 2004, pp. 50-80). Debido a esta condición de 
locus classicus (Serwin-White 1970, p. 71) ${ }^{1}$ y a la posible influencia en su escritura de algunos epigramas de $\mathrm{Marcial}^{2}$, la crítica ha proyectado sobre el epigramista la helenofobia del satírico, apoyándose, entre otros argumentos, en el silencio que el bilbilitano mantiene con respecto a sus modelos griegos ${ }^{3}$. Marcial habría adoptado así una actitud nacionalista afirmativa de la cultura romana, con sus tradiciones y valores, frente a la griega.

Nuestro propósito es estudiar aquí la visión de los griegos que nos ofrece la obra de Marcial, un aspecto de la misma apenas estudiado de manera específica ${ }^{4}$. Como vamos a ver, su visión es más compleja que la de Juvenal y difiere bastante de la que este expresa en el pasaje mencionado. Pero, antes de entrar en el análisis de los epigramas relacionados con este tema, conviene que hagamos referencia, tanto a los principios que van a guiarlo, como al furibundo ataque de Juvenal contra los griegos que nos sirve de término de comparación y contraste.

Empecemos por ver cómo aparece representada la alteridad de los griegos en la literatura romana anterior. La ambivalencia que los romanos adoptaron hacia los griegos aparece magistralmente resumida por Horacio en Ep. II 1,156-57 - Graecia capta ferum uictorem cepit et artis / intulit agresti Latio.- Al tiempo que manifestaban admiración por la cultura griega del pasado, se sentían superiores a los griegos contemporáneos sometidos por ellos y empezaron pronto a crear el estereotipo negativo que encontraría su forma extrema en el texto de Juvenal. Los romanos construyeron un carácter del griego opuesto al que se atribuyeron a sí mismos: frente a la uolubilitas, ineptia, leuitas y tendencia a la mendacidad y el afeminamiento de los griegos, se elevaban la grauitas, dignitas, pietas y valor militar de los romanos (Alcok 1993, p. 29). En mayor o menor medida el estereotipo negativo y la desconfianza hacia los griegos se encuentra en autores, que no dejaban de

1 También Shumate 2006, p. 32, encuentra en este pasaje la estructura genérica de los discursos xenófobos, que en los dos últimos siglos ha producido el nacionalismo moderno.

${ }^{2}$ Colton 1991, pp. 97-110, recoge varios epigramas, que en su opinión han sido tenidos en cuenta por Juvenal en III 58-125. Veremos más abajo el alcance de tal influencia.

${ }_{3}$ Para Sullivan 1991, p. 93, este silencio es la prueba de que comparte el odio de su amigo Juvenal por los griegos. Beltrán 2005, p. 71, se suma al argumento ofrecido por Sullivan y también Socas 2006, p. 344, aunque no lo cite.

${ }^{4}$ Socas 2006 solo le dedica unas páginas (344-346), en las que se limita a comentar sin detenerse demasiado el X 65, un pasaje del IX 11 (13-17) y X 76, cuyo blanco, según el mismo señala, son los extranjeros advenedizos en general. 
admirar por ello la cultura griega ${ }^{5}$. El grado de distancia o de desprecio con respecto al «otro» griego se corresponde con la fuerza que encuentre en cada escritor la afirmación de su identidad nacional y cultural: cuanto mayor sea su nacionalismo, mayor rechazo manifestará hacia los que no se cuentan entre los «suyos», no pertenecen a su etnia, no hablan su lengua ${ }^{6}$ ni comparten sus valores y costumbres.

Por otra parte, la forma de dar expresión a estos sentimientos dependerá también de las convenciones del género literario, del público al que se dirige y de la posición del autor en la literatura y cultura romanas, así como de sus orígenes dentro del vasto espacio del imperio ${ }^{7}$. De modo que, para establecer las diferencias entre las visiones particulares que Marcial y Juvenal nos ofrecen de los griegos, conviene tomar en consideración todos estos factores.

Por último, antes de pasar a Marcial, vamos a examinar brevemente y en términos generales la visión del «otro» griego de Juvenal, ya que no nos faltarán ocasiones de referirnos de forma más concreta a ella a lo largo del trabajo.

Juvenal muestra con frecuencia hostilidad hacia los extranjeros que en su tiempo se habían establecido en Roma y medraban en la capital en detrimento de los nativos ${ }^{8}$; pero contra ningún grupo lanza una invectiva tan arrolladora como la que les dedica a los griegos en III 58-125, sin que esto les exima de otros ataques más o menos puntuales que emergen con frecuencia a lo largo de su obra. En esta sátira es Umbricio, un amigo del satírico que se marcha de Roma, el que pronuncia la tirada contra los griegos. Aunque últimamente la crítica ya no considera a Umbricio un simple alter ego de Juvenal y señala la distancia irónica del satírico con respecto al portavoz de

${ }^{5}$ Cicerón ofrece bastantes ejemplos de esta ambivalencia, como ha estudiado Syed 2005, pp. 364-366. Un estudio más completo de los autores, que adoptan una actitud doble hacia los griegos, se encuentra en Isaac 2004, pp. 380-405.

${ }^{6}$ Sobre el conocimiento de la lengua latina como afirmación de la romanitas v. Adams 2003, pp. 184-205.

7 Aunque el lugar de origen de cada uno de los autores en el marco del imperio no parece desempeñar ningún papel en las expresiones de la visión del «otro», pues en general todos adoptan el punto de vista de «romano» (Syed 2005, p. 361), creemos que en este caso debe ser tenido en cuenta, ya que, como vamos a ver, los conceptos de centro y periferia (Barchiesi 2005, p. 401) nos ayudan a explicar las diferentes visiones de los griegos que presentan Marcial y Juvenal.

${ }^{8}$ Isaac 2004 recoge y comenta sus ataques contra los egipcios (pp. 363 s.), los sirofenicios y los capadocios (pp. 340 s.), los griegos (pp. 395-97) y los judíos (pp. 364 s.). 
la mayor parte de la sátira $(21-322)^{9}$, siguen señalándose coincidencias entre ellos y una de ellas es la xenofobia, ya que en la introducción el satírico manifiesta su disgusto por los inmigrantes judíos, que tienen tomado el bosque sagrado de Numa (12-14); y por el mármol extranjero que contamina la pureza de las grutas del valle de Egeria (17-20).

Umbricio abandona Roma porque no encuentra en ella lugar para los trabajos y los ciudadanos honrados (21ss.); en la Vrbs solo triunfan quienes no tienen escrúpulos y, como él no sabe mentir, ni adular, ni convertirse en cómplice de delitos mayores (41 ss.), no tiene nada que hacer allí. Pero la causa principal de su partida es que, como cliens, ha sido desplazado de las casas de los ricos por los inmigrantes griegos. Si en los primeros versos parecía dirigirse solo a Juvenal (21-57), ahora, para lanzar su invectiva, eleva la voz y apostrofa a los ciudadanos romanos: non possum ferre, Quirites/Graecam urbem (60-61). En estos versos iniciales encontramos ya el punto de vista nacionalista del que parte el ataque, el particular sentido de la romanitas que aquí se afirma frente a los griegos ${ }^{10}$. Y elige para empezar con la retahíla de cargos contra ellos a los griegos del Este, un torrente de «heces» que ha venido a desembocar en el Tíber para contaminar hasta al más rústico de los romanos, que ahora usa calzado griego y luce las medallas ganadas en los juegos (62-68). Al principio parece excluir del ataque a Atenas — quamuis quota portio faecis Achaei? (61) - ; pero a continuación deja claro que se refiere también a griegos procedentes de la Grecia continental y de las islas ${ }^{11}$ : como un ejército en formación vienen a tomar las mansiones de los ricos y a hacerse los amos en ellas (69-72).

9 Cortés Tovar 2007, pp. 52-57, recoge la discusión y justifica la idea de que el satírico se distancia de Umbricio analizando la sutil ironía que empieza a aparecer ya aquí en la obra de Juvenal.

${ }^{10}$ Shumate 2006 dice que Juvenal construye la romanitas y el «nosotros» negativamente, como diferente de los «otros» (pp. 19-21), pero como nacionalista reaccionario ofrece una visión reductiva de la romanitas, que se cierra sobre sí misma, cuando el mundo real se estaba ampliando y haciéndose cada vez más romano.

${ }^{11}$ Isaac 2004, p. 396, dice que Juvenal no diferencia entre los griegos de la Grecia continental y los de las provincias del Este. Socas 1995, p. 158, en cambio, cree que el satírico soportaría a los griegos de Atenas, porque los que menciona vienen de todas partes menos de allí. Aunque la cuestión quota portio ... no supone exclusión absoluta de los griegos de Atenas y el ejemplo de Dédalo (80) refuerza que tiene también en su punto de mira a los atenienses, es cierto que evita acusar a los representantes mayores de esa cultura griega, que incluso los romanos chovinistas xenófobos con los griegos de su tiempo, excluían de sus ataques, como hemos señalado más arriba. 
La razón de su éxito se encuentra en su «rápido ingenio», su audacia y su facilidad de palabra (73-74); y en que se ofrecen a desempeñar todos los oficios posibles e imposibles (74-80): a todo se atreve un graeculus esuriens (79). El hambre, tan despreciativamente subrayada, lo ayuda a sobrepasar al cliens romano, que vive en una ambitiosa paupertas, en una "pretenciosa pobreza»; y lo peor es que lo supera en actividades que probablemente Umbricio podía desempeñar muy bien en casa de sus patroni ricos, especialmente las intelectuales, como grammaticus, rhetor o geometres, que él, como severo romano, consideraría honestas.

Con sus múltiples habilidades los griegos lo han desplazado: firman antes que él documentos legales como testigos y ocupan un lugar mejor en el banquete, unos individuos a los que equipara despectivamente con productos de importación como «las ciruelas y los higos» en contraposición a su infancia nutrida con las aceitunas sabinas y el aire puro del Aventino (81-85). A él, un nativo, lo tratan peor que a unos inmigrantes empujados a Roma por el hambre. Aparecen de forma clara las razones de su resentimiento: ha perdido las oportunidades que le daba la amistad con los poderosos, la posibilidad de lograr algún cargo en la militia equestris o algún puesto en la administración imperial (Sherwin-White 1970, p. 79).

A partir de aquí se suceden las acusaciones más hirientes y xenófobas: los griegos son capaces de las adulaciones más abyectas (86-93) y consiguen que los crean, porque son tan buenos comediantes que bordan los personajes femeninos hasta sugerir incluso cambios en su anatomía (94-97): natio comoeda est (100), dice el satírico generalizando su ataque a «todos los griegos» como radicalmente diferentes de los romanos de pura cepa. Pero a continuación vienen cargos mayores: como señala Socas 1995, p. 161, la lascivia se suma siempre a la «cantinela incansable de la xenofobia». Los griegos no respetan nada: praeterea sanctum nil restat ab inguine tutum (109). Nadie está seguro en la casa que los acoge; no distinguen ni edades ni sexos. Con frecuencia se les atribuyen a los extranjeros los rasgos de otros grupos de «otros», como los de las mujeres y los homosexuales (Shumate 2006, pp. 19-20). Pues bien, aquí son capaces de todo tipo de desviaciones: pueden hacerse pasar por mujeres y mantener relaciones sexuales delictivas tanto heterosexuales como homosexuales; y como si la mención de estas relaciones le recordara la aversión que los romanos tenían al gymnasium como lugar de perversión homosexual, pasa por alto los gimnasios como lugares de delitos menores (115) para pasar al clímax de su condena: la traición de un 
griego que, por delación, llevó a la muerte a su patrono y amigo Bárea Sorano en tiempos de Nerón. Este crimen, con mayor o menor efecto, lo cometen los griegos constantemente para desplazar de las casas de los ricos a los viejos clientes romanos. Basta con que viertan en el oído del magnus amicus una gota de naturae patriaeque ueneno,/limine summoueor: Umbricio es expulsado después de años de servicio en la casa, sin darle la menor importancia (123-125). Vuelve así Juvenal a recoger al final la causa del resentimiento, la exclusión del viejo cliens y también, conviene subrayarlo, la generalización del crimen de la delación a toda la graeca patria, como diferente de la romana.

Creo que con este repaso al texto de Juvenal queda claro el carácter masivo, generalizador e inapelable de su condena de los griegos como pueblo. Pues bien, si se lee la obra de Marcial detenidamente buscando en ella todos los epigramas y pasajes referidos a los griegos no encontramos nada semejante al ataque de Juvenal: son muy pocas las referencias a grupos de griegos de diversas áreas geográficas del mundo helenizado, y también son escasas las chanzas contra personajes particulares, claramente identificables por sus nombres como griegos, por su condición de tales ${ }^{12}$. De todas formas, para llegar a conclusiones fundamentadas sobre la visión de Marcial de los griegos, debemos analizar todos los pasajes de su obra que tengan que ver con ellos de forma más o menos explícita e incluso sus silencios.

Así que empezaremos por el silencio del epigramista a propósito de sus modelos griegos, señalado por algunos críticos como prueba de que comparte el odio de su amigo Juvenal por el pueblo griego, por la graeca natio. De entrada no es verdad que Marcial calle sobre todos los epigramistas griegos, puesto que menciona a Calímaco en IV $23^{13}$. El poeta alejandrino es el primus en el canon del epigrama griego en la Roma Imperial ${ }^{14}$ y el modelo de referencia para los romanos que cultivaban el epigrama en la tradición griega.

${ }^{12}$ Quizás por eso no aparece Marcial en el libro de Sherwin-White 1970, a pesar de que el último capítulo está dedicado a «Strife and Rivalry Within the Empire» (62-101). Tampoco lo encontramos en el capítulo que le dedica Isaac 2004 a «Roman Views of Greecks» (pp. 381-405).

${ }_{13}$ Paradójicamente Sullivan 1991, p. 60, comenta este epigrama.

14 También Plinio, Ep. IV 3,3-4, lo menciona como modelo indiscutible de Arrio Antonino, escritor de encantadores epigramas griegos (Puelma 1997, p. 192). Más recientemente Citroni 2004, p. 8, n. 10, cree que Marcial y Plinio conocieron una colección de epigramas de Calímaco, aunque no es posible saber si el propio poeta los publicó de manera autónoma. 
Irónicamente Marcial lo representa cediéndole la palma a uno de ellos, al enigmático Brutiano ${ }^{15}$, empapado en «gracia cecropia», pero al que nuestro epigramista solo seguiría, si a aquella le añadiera en sus «juegos» la sal romana (Romanae sale luserit Mineruae, 7); es decir si Brutiano incorporara a la tradición griega el sentido del humor romano, picante y mordaz, e integrara en su obra las dos tradiciones, la griega y la romana. Esta condición la cumple el propio Marcial en su obra ya a la altura de este libro cuarto; de manera que lo que parece estar sugiriendo sutilmente es que ningún romano puede rivalizar con él (Moreno Soldevila 2006, p. 227).

Además, y esto no creo que haya sido suficientemente subrayado, él es el único comparable a Calímaco, su único equivalente en la literatura latina, porque es el primero que le ha dado una denominación estable al género en Roma y una forma que, manteniendo el predominio del dístico elegíaco de la tradición griega, ha sabido incorporar a ella hábilmente dosificados los metros más relevantes de su modelo romano $\mathrm{Catulo}^{16}$ y los temas romanos contemporáneos. No puede ser gratuito el hecho de que en este mismo libro (IV 14,13-14) se compare también con Catulo, que aparecerá más tarde (I ep.10) encabezando el canon de los cultivadores romanos del género. Por medio de esta doble comparación indica de manera indirecta que las tradiciones encabezadas por Catulo y Calímaco han sido integradas en su obra y que a partir de ellas ha llevado a cabo la canonización del género en latín. Pero en este proceso al bilbilitano le interesaba más concentrarse en la creación de una tradición romana para el epigrama que citar a otros modelos griegos puntualmente presentes en su obra. La lista de predecesores romanos, según la encontramos en la epístola del libro primero, se iría formando con el tiempo y solo estaría completa para la segunda edición en códice de los siete primeros libros ${ }^{17}$. Antes ya encontramos a Marso y Catulo nombrados juntos

${ }^{15}$ Sobre la posibilidad de que fuera Cerrinius (VIII 18,1), un amigo de Marcial que escribía epigramas en griego, quizás por no competir con él, cf. Moreno Soldevila 2006, p. 228.

16 Según Citroni 2004, pp. 15-17, Marcial utiliza el dístico en un 73,1\% de los poemas, el endecasílabo en el 19,4\%, el coliambo en el 6,4\% y en un $1 \%$ otros metros. La distribución es equilibrada a lo largo de toda la obra y similar a la que se aprecia en el libro de Catulo.

${ }^{17}$ La crítica en general acepta que la Epistola introductoria al libro I y los dos primeros epigramas del mismo (I 1 y I 2) pertenecen a esa segunda edición. Menor seguridad hay sobre la fecha de esa segunda edición (¿93?) y sobre los libros que comprendía (Citroni 1975, pp. XIX-XX). Los argumentos a favor de la inclusión en ella de los siete primeros libros nos parecen convincentes (Laurens 1989, p. 218). 
en II 71 y en el epigrama que cierra el libro séptimo (VII 99), nombres a los que añade el de Pedón en V 5, donde le pide al encargado de la biblioteca Palatina que ponga sus libros junto a los de aquellos en el espacio dedicado al epigrama latino. De modo que el silencio sobre los demás epigramistas griegos que influyeron en su obra no necesariamente se debería a su helenofobia, sino a su decisión de priorizar en su poética a los poetas romanos, ya que es a la literatura romana a la que le hace una aportación de primer orden.

Muy diferente es la posición que Juvenal ocupa en la literatura romana al cultivar un género, que ya había definido Quintiliano como enteramente romano: Satura quidem tota nostra est (Inst. X 1,93). En este género Juvenal solo tenía que afirmar sus modelos romanos y adoptar una actitud etnocéntrica desde la $V r b s$, el corazón del imperio. No tiene que definir la romanitas de la sátira en competencia con una tradición griega del género, como le ocurre a Marcial con el epigrama, ni citar a ningún auctor griego del mismo. En este terreno, sencillamente puede olvidarse de ellos. Ni siquiera cuando evoca la poesía mitológica que rechaza en su sátira programática (sobre todo I 1-11; 161-164), evoca ni alude a los poetas griegos ${ }^{18}$.

Marcial, en cambio, sí lo hace: rechaza Aetia de Calímaco en X 4,12 como obra emblemática de la poesía mitológica, ficticia y sin contacto con la vida y los mores, que constituyen la esencia de sus epigramas. No vemos aquí ninguna motivación xenófoba aparente, pues de la misma forma alude críticamente en II 86 al poema 63 de Catulo. Pero en este epigrama no se limita a negarle interés a la poesía de tema mitológico; va más allá: se distancia de los derroteros que los seguidores de Calímaco y de los neotéricos habían tomado después de Augusto, con sus metros artificiosos y efectistas. El epigramista afirma que él no escribe versos palíndromos, ni obscenos sotadeos —Sotaden cinaedum (2) - , ni versos echoici — nusquam Graecula... recantat echo (3) - ni blandos galiambos — nec dictat mihi luculentus Attis/ mollem debilitate galliambon (4-5)—, porque emplearlos en una poesía espontánea y viva como sus nugae, sería casi caer en un oxímoron: Turpe est difficiles habere nugas let stultus labor est ineptiarum (9-10).

Resulta curioso que solo en este poema, de todo el corpus de Marcial, aparezca un término clave en la expresión de la hostilidad de los romanos hacia los griegos: Graecula, un término que en poesía romana solo aparece, además, en Juvenal III 78 y VI 186. Dubuisson 1991, p. 325, sostiene que el

${ }^{18}$ v. las detalladas notas de Cortés Tovar 2007, pp. 214-229, a esta sátira. 
término en Marcial tiene solo un valor técnico para referirse a un metro que es identificado como griego, sin intención peyorativa. Mattiacci (2007, p. 175), que señala alusiones a Persio I 92-102 en el epigrama, cree que Marcial solo está haciendo crítica literaria. Ahora bien, veamos más despacio las alusiones ${ }^{19} \mathrm{y}$ los contextos. El satírico parodia en los versos mencionados la poesía neocalimaquea que se cultivaba en el círculo neroniano y la condena como síntoma de la decadencia moral de Roma: frente a los valores nacionales sintetizados por él en el virgiliano arma uirum (96), la poesía a la que se entregan ahora los romanos no tiene fibra alguna de la virilidad paterna: testiculi uena ulla paterni (103). El epigramista, por su parte, emplea términos referidos a la sexualidad y especialmente a la pasividad sexual — cinaedum y mollem — ${ }^{20}$, que leídos sobre el trasfondo del intertexto persiano también parecen apuntar a una crítica a la falta de virilidad de la poesía que utiliza tales metros. En ninguno de los dos poetas tenemos ataque contra los griegos, porque son los romanos los que han adoptado y llevado al extremo la poética calimaquea, con la consiguiente pérdida de fuerza e inclinación a la mollities. Romanos son también el aludido Catulo y el famoso gramático Palemón mencionado al final del epigrama, que según Suetonio compuso, en efecto, versos en metros inusuales ${ }^{21}$; pero se trata de romanos contaminados de alguna manera por los rebuscados ritmos de la poesía helenística.

Aquí subyace el prejuicio contra la tendencia al artificio y afeminamiento de los griegos, encarnado en este caso en rasgos característicos de la poesía alejandrina. Más que ataque xenófobo implícito contra los griegos, lo que critica es el filohelenismo exacerbado ${ }^{22}$ y lo hace sin excesiva agresividad, porque en realidad su propósito es señalar la falta de adecuación de los ritmos blandos al carácter de su obra, a la que tantas veces identifica con la mentula: I 35; III 69; XI 90 etc. (Williams 2002, pp. 158-170). A esta concepción fálica del epigrama responde sin duda que, cuando desliza alguna nota des-

${ }^{19}$ El intertexto de Persio late en los finales de dos versos de Marcial: Berecyntius Attis (I 93) en luculentus Attis (II 86,4) y adsonat echo, (I 102) en recantat echo, (II 86,3).

${ }^{20}$ Cf. el comentario de Williams 2004, p. 260, sobre el significado sexual de algunos de los términos que aparecen en este epigrama, especialmente cinaedum (2) y mollem debilitate galliambon (5).

${ }^{21}$ Cf. De Gramm. 23: nec non etiam poemata fecit ex tempore: scripsit uero uariis nec uulgaribus metris.

${ }_{22}$ Marcial no evita enteramente los efectismos métricos, como podemos ver en V 24; VII 18 y IX 57, pero no se excede en ellos (Williams 2004, p. 260). 
pectiva contra los griegos, siempre se refiere a su mollities: así en $S p$. 1,3 los jonios aparecen como molles, blandos o sexualmente pathici.

Así pues, por lo que hemos visto hasta ahora, Marcial mantiene sus distancias con respecto a algunas modas calimaqueas adoptadas por los romanos, pero sin dejar de reconocer a Calímaco como representante principal de la tradición griega del epigrama, aunque, debido al cometido que se había propuesto de dotar de identidad romana al epigrama, afirma su romanitas. De acuerdo con ella, el trasfondo de su obra es enteramente romano: calles y monumentos son romanos, los mores y la vida representada en ellos también lo son y, sobre todo lo son mayoritariamente los intertextos presentes en su obra: de Catulo y los poetas augústeos (Rimell 2008, pp. 6-7). Parece claro que la meta de Marcial era incorporar este género menor al canon de los géneros poéticos reconocidos en Roma; de ahí que subraye su romanitas cultural y literaria.

Ahora bien, esto no impide que a veces recuerde el trasfondo cultural grecorromano de su obra y la de sus amigos: en IV 86 exhorta a su libro a gustarles a los «áticos oídos» del docto Apolinar (1-3); en la secuencia proemial del libro V la diosa Minerva, protectora de Domiciano, es calificada alternativamente como «Cecropia» (V 2,8) y latina o, más exactamente, «Palatina» (V 5,1); en I 25,1-4 invita al docto Faustino a publicar sus libros, que le gustarán tanto a griegos como a romanos, de gustos más severos; en la alabanza a su amigo Deciano en I 39,23 Minerva es cecropia y latina al mismo tiempo; y el poeta Mevio, pobre y maltratado por la Fortuna, escribe poesía en ambas lenguas (X 76).

Encontramos también las dos culturas unidas en XI 53, un epigrama de alabanza a una matrona que, a pesar de descender de los «cerúleos britanos», sería considerada romana por las itálicas y «suya» por las atenienses; y en VI 64 le concede irónicamente a un crítico de su obra un gusto supremo, formado tanto por la Minerva romana como por la elegante Atenas.

No son muchos los epigramas en cuyo trasfondo aparece la cultura común grecorromana; pero son suficientes para mostrar que para Marcial la cultura griega sigue siendo un paradigma respetable. Naturalmente ese fondo cultural común no se identifica con cualquier lugar del imperio, pues en la mayoría de los epigramas en que aparece se repiten las referencias a Atenas/Ática y Roma/Italia; es decir, los lugares centrales de ambas culturas. El hecho de que en el caso de Grecia el referente sea siempre Atenas, encarnación de los logros literarios y artísticos de los griegos del pasado, tan admirados por los romanos, corrobora que Marcial no se aparta de la visión tradicional que estos tenían de los griegos, ahora en su vertiente positiva: de la Atenas clási- 
ca habría venido el núcleo central y originario de la literatura y la cultura que los romanos supieron asimilar tan bien a la suya.

Apreciamos así en Marcial una visión de los griegos en el ámbito literario y cultural más compleja que la que nos proporciona la interpretación de su relativo silencio sobre ellos. Pero pasemos ahora a ver hasta qué punto la influencia de los epigramas de Marcial en Juvenal ha sido tan determinante de su ataque contra los griegos como para legitimar la atribución al epigramista de una actitud equiparable a la del satírico.

Para Colton 1991, Juvenal ha tomado la descripción del versátil graeculus esuriens de sus vv. 76-77 de Marcial II 7, un epigrama dirigido a un tal Atticus que cultiva «bonitamente» - belle - actividades intelectuales diversas -rétor, abogado, historiador, poeta lírico, autor de mimos y epigramas, gramático- y otras menos aceptables desde el punto de vista romano - es astrologus, canta, baila, toca la lira y juega a la pelota-; pero sin realizar bien ninguna de ellas: nil bene cum facias, facis tamen omnia belle (v. 7). Es un gran ardalio, un diletante excesivo e inoportuno. Colton afirma que se trata de un liberto griego. Pero no encontramos tal información en Marcial, porque no es frecuente que dé indicaciones explícitas sobre la condición social de las víctimas de su chiste ${ }^{23}$. El nombre, de todas formas, lo caracteriza como griego, circunstancia que se vería corroborada porque el graeculus en Juvenal también sabe (omnia nouit) desempeñar múltiples oficios: gramático, rétor, geómetra, médico, entrenador, funámbulo, masajista y mago ${ }^{24}$.

Las semejanzas están claras; pero apenas se señalan las diferencias y la nueva función que el intertexto de Marcial cumple en la sátira. Recordemos que el satírico ataca a los griegos como competidores de los honrados clientes romanos en las grandes casas del Esquilino y el Viminal; de ahí el alcance generalizador de su furibundo ataque, que hemos subrayado antes. Marcial, en cambio, solo critica y se burla de un individuo al margen del contexto de las relaciones de clientela, tan relevantes también en su obra. Le llama Atticus intencionadamente para subrayar sus pretensiones de ser una especie de com-

${ }^{23}$ Normalmente no dice si se trata de un libertus, un liber de origen humilde o un generosus empobrecido: Malnati 1988, p. 140.

${ }^{24}$ Como señala Colton 1991, p. 101, algunos oficios coinciden con los de Atticus: gramático, rétor y adivino (astrologus/augur); los dos se relacionan también con el mundo del espectáculo y la gimnasia (músico el uno, funámbulo el otro). Juvenal introduce profesiones nuevas, como geómetra y médico. Las diferencias no anulan la capacidad para abarcarlo todo subrayada en ambos textos. 
pendio de la cultura griega, de la que hace evidente ostentación: no se dedica solo a actividades respetadas por los romanos como la retórica, gramática, abogacía y diversos géneros literarios, sino que también cultiva otras que aquellos consideraban sospechosas, como la astrología, o poco serias como el canto, la danza, juego de pelota, etc. (Williams 2004, p. 46). Aunque el nombre podría cuadrarle también a un romano helenófilo, el insulto final ardalio nos lleva a pensar en un graeculus oficioso y adulador. Este término solo aparece en Fedro II 5 y en Marcial IV 78 y en ambos casos el ardalio se desvive por agradar a personas importantes de las que pueda sacar algo ${ }^{25}$. Aunque Marcial en II 7 no es tan explícito - ni siquiera lo presenta como cliens potencial - y se limita más bien a desenmascarar irónicamente al personaje, la insinuación en el fulmen final parece clara; de manera que su retrato de Ático se adaptaba perfectamente a las necesidades de Juvenal, que al incorporarlo a su sátira lo convierte en el graeculus prototípico, arribista que seduce con su «sabiduría» universal a los nobles romanos, y despierta la ira de los pobres clientes excluidos.

El nombre Atticus aparece otras dos veces en Marcial: en VII 32 y en IX 99. Estos textos no han sido puestos en relación con el primero. Del IX 99 podemos prescindir porque Attice solo aparece como interlocutor en el v.1 y no se nos dice nada de él. En cambio VII 32 nos interesa porque cabe la posibilidad de que Marcial haya utilizado el nombre Atticus en II 7 para establecer una relación intratextual antitética entre ellos. Frente al carácter ficticio del primero (Williams 2004, p. 46), el Ático del segundo es un descendiente de Pomponio Ático, el amigo de Cicerón, al que el epigramista alaba por su dedicación a las artes de la cecropia Minerva (especialmente a la filosofía epicúrea), y por su rechazo de los ejercicios de la palestra griega tan cultivados por otros jóvenes romanos. Ático, en cambio, prefiere practicar deportes genuinamente romanos ${ }^{26}$. La relación intratextual entre ambos epigramas intentaría subrayar cómo el descendiente de Ático sabe adoptar lo que

${ }^{25}$ En Fedro la definición del ardalio sirve de promythium: Est ardalionum quaedam Romae natio,/trepide concursans, occupata in otio,/gratis anhelans, multa agendo nihil agens,/ sibi molesta et aliis odiosissima (1-4). A continuación narra una anécdota en la que un ardalio intenta conseguir inútilmente el favor de Tiberio. Marcial en IV 78 le aplica el término a un anciano, que, sin el decorum requerido por su edad, se comporta como adulador incansable y servil. El término aparece también en CIL IV 4765.

${ }^{26}$ Galán Vioque 2002, p. 225, recoge las críticas de numerosos autores romanos, que pueden resumirse con las palabras de Tácito, Ann. XIV 20,4: degeneretque studiis externis iunentus, gymnasia et otia et turpis amores exercendo. 
los romanos consideraban bueno de los griegos frente al ardalio de II 7, que, en su intento de agradar, se traicionaba pensando que todos los aspectos de la cultura griega eran igualmente apreciados por los romanos. Estaríamos de nuevo ante esa dualidad tradicional hacia lo griego que hemos señalado antes: frente al rechazo del primer Atticus, el segundo es alabado porque sabe acercarse a la cultura griega desde su lealtad a los valores romanos.

Los otros epigramas señalados como inspiradores de Juvenal tienen una cercanía más explícita con el contexto del ataque del satírico, porque tratan sobre las relaciones de clientela, especialmente el XII 82. En este, el epigramista nos describe a un Menógenes hambriento que anda a la caza de una invitación a cenar, y es tan pesado en su adulación que consigue su propósito a base de cansar a su víctima: Omnia laudabit, mirabitur omnia, donec/ perpessus dicas taedia mille: 'Veni' (13-14). El nombre Menógenes es también griego, pero el epigramista no se refiere explícitamente a su origen. Este personaje comparte muchos de los rasgos del graeculus esuriens adulador juvenaliano: las comparaciones con héroes mitológicos que ambos emplean para convertir los defectos de sus potenciales patroni en virtudes -con Aquiles en el epigrama (9-10); con Hércules en la sátira (88-89)- y los mismos verbos para referirse a su adulatio: laudat/sermonem indocti (86-87) y miratur uocem angustam (90) (Colton 1991, p. 104); pero mientras los graeculi de Juvenal, la adulandi gens prudentissima (86), consiguen seducir a los magnates romanos e instalarse en sus casas, Menógenes solo obtiene una victoria ocasional, puesto que no logra engañar a su víctima. De ahí la diferencia de tono entre la ira de Umbricio y la distancia irónica del epigramista.

De otros dos epigramas recoge Colton ecos puntuales en el texto de Juvenal: los aplausos a la recitación de un patronus en X 10,10 — geminas tendis in ora manus - laten en iactare manus laudare paratus de Juv. III 106, mientras el verso que le sigue (107) si bene ructauit, si rectum minxit amicus, actividades que el graeculus está «dispuesto»a aplaudir, estaría inspirado en el epigrama III 82, 8-9 y 15-17.

Estos dos epigramas (X 10 y III 82) también representan las relaciones de clientela, pero en ellos no aparecen en absoluto los griegos compitiendo con los pobres y honrados clientes romanos por el favor de los patroni. El adulador de X 10 es un cónsul romano que con su púrpura y su obsequioso comportamiento desplaza a los pobres togados (12). Aunque Juvenal también se queja de la desleal competencia de los magistrados (I 101), no les atribuye la actitud aduladora que proyecta sobre los competidores griegos. 
En cuanto al intertexto de III 82 hay que decir que es el que más diferencias mantiene con respecto al texto de Juvenal. Está dedicado al ostentoso banquete de Zoilo, un nuevo rico, que comparte rasgos con la cena de Trimalción ${ }^{27}$. Entre otras vulgaridades se describen los mismos desahogos fisiológicos que en Juvenal III 107; pero mientras en el satírico es el graeculus adulador el que aplaude los eructos y la correcta micción de su patronus romano, en Marcial a Zoilo lo ayudan sus esclavos a aliviarse. Los clientes invitados a la cena, aparentemente romanos, se limitan a aguantar estas groserías y la discriminación a que los somete el anfitrión al servirles una comida peor que la que les arroja a los perros que merodean en torno a su mesa. No se menciona a los griegos en el epigrama; y Zoilo, si era un liberto griego como parece indicar su nombre, está aquí en posición de superioridad, la contraria de la que los graeculi mantienen en el texto de Juvenal.

De modo que Juvenal aprovecha textos de Marcial en los que este o no menciona a los griegos o, cuando lo hace, se refiere a ellos como individuos, no como representantes de la graeca natio. Solo Atticus, por el carácter emblemático de su nombre puede tener un alcance más general (Vallat 2008, pp. 485-486); pero el tono ligero e irónico de su crítica está muy lejos del ataque masivo y lleno de odio de Juvenal.

Por otra parte, los epigramas de Marcial que más peso tienen en el locus classicus de Juvenal, el II 7 y el XII 82, no nos permiten determinar con precisión el punto de vista desde el que el epigramista critica a Ático y Menógenes, pues, al no señalarlos explícitamente como griegos y no aparecer en una secuencia de epigramas sobre el mismo tema que aclare la actitud del poeta, no podemos afirmar que Marcial esté adoptando una posición nacionalista y xenófoba, como la que encontramos en el texto de Juvenal.

La razón de la diferencia entre ellos puede estar en que responden a distintas concepciones de la romanitas. Para Juvenal esta, como hemos visto más arriba, solo la encarnan los nacidos en Roma o Italia; los demás son todos extranjeros; para Marcial la romanitas tiene una dimensión imperial ${ }^{28}$.

${ }^{27}$ Sullivan 1991, p. 111, señala algunos detalles comunes entre los dos libertos, además del nombre: Malchio (32). Para Watson \& Watson 2003, pp. 270-72 «La cena de Trimalción» es el modelo principal de Marcial. Sobre las diferencias entre ambos personajes cf. Leâo 2004, pp. 191-208.

${ }^{28}$ En él ya encontramos ese punto, en el que, según Cizek (1989, p. 367) en su estudio del desarrollo histórico de la «imagen del otro», «l'étranger vivant à l'interieur de l'Empire» deja de existir y «l'opposition entre citoyen romain et pérégrin n’est pas pertinente». 
Roma es el centro de un Imperio multicultural, que se resume y sintetiza en su microcosmos (Rimell 2008, p. 8). Como ha señalado la crítica más reciente, los primeros poemas del Liber Spectaculorum de Marcial transmiten magistralmente esta idea: el Coliseo sustituye (o representa) al resto de las maravillas del mundo como una metáfora del dominio universal de Roma (1) y los pueblos más diversos por sus orígenes, atuendos y lenguas se unen y confunden en la lengua única con la que aclaman al emperador (3) ${ }^{29}$. Más allá de la propaganda del poder Flavio, representada y legitimada en la arena del anfiteatro y poetizada por Marcial ${ }^{30}$, este encuentra en el espacio del Imperio el terreno adecuado para la expansión de su fama como poeta. Al tiempo que el epigrama conquista el globo (totus notus in orbe, I 1,2; V 13,3; X 9,3-4 etc.), también lo coloniza y pone a Roma en los lugares más remotos del Imperio: el epigrama viaja por toda la topografía romana porque hasta sus propios lectores le sirven a la Vrbs de embajadores ${ }^{31}$; gentes de todo el mundo acuden a Roma y Roma está en todas partes, desde Bílbilis a los desiertos de Cartago y Escitia (X 13). Esta perspectiva imperial de Marcial sería sin duda determinante de una visión bastante tolerante del otro, de los múltiples «otros» dentro del imperio y especialmente de los griegos. La xenofobia en los epigramas no habría favorecido su éxito mundial; además los habitantes de la periferia del imperio posiblemente habrían considerado intolerable que un provinciano como ellos atacara su lengua o sus costumbres $^{32}$.

${ }^{29}$ Cf. los interesantes análisis de la secuencia de apertura del libro que nos ofrecen Gunderson 2003, p. 652 y Fitzgerald 2007, pp. 38-40, que llegan a la conclusión de que en ella se borra la distancia entre lo extranjero y lo romano.

${ }^{30}$ Sobre la significación del Coliseo y de la arena para prestarle a los Flavios la auctoritas y dignitas que les faltaban por sus orígenes v. Gunderson 2003, pp. 640-643. Asimismo Coleman 2006, p. LXXIV señala que, al recuerdo permanente de la prouidentia flavia asociado al monumento, se unió la poesía de Marcial que monumentalizó los juegos efímeros celebrados en él.

${ }^{31}$ Rimell 2008, pp. 182-185. También señala esta autora que en los epigramas de Marcial visualizamos mejor a Roma como Imperio que en la Historia Natural de Plinio el Viejo o en el Agrícola de Tácito (p. 8).

32 De hecho, aunque Sullivan se empeña en afirmar que Marcial comparte la xenofobia de otros escritores romanos, cuando hace un repaso de epigramas «xenófobos», obtiene resultados magros y referidos solo a algunos pueblos: respeta a los dacios y los sármatas, juega con el significado obsceno de gallus, y lanza algunos ataques contra los judíos, los germanos y los africanos (1991, pp. 169-170). 
De todas formas, encontramos un único epigrama en la obra de Marcial (X 65) contra un griego de Corinto por su condición de griego, pero el punto de vista xenófobo no corresponde al Marcial romano imperial, sino al Marcial hispanus:

Cum te municipem Corinthiorum iactes, Charmenion, negante nullo, cur frater tibi dicor, ex Hiberis et Celtis genitus Tagique ciuis? an uoltu similes uidemur esse? Tu flexa nitidus coma uagaris, Hispanis ego contumax capillis; leuis dropace tu cotidiano, hirsutis ego cruribus genisque; os blaesum tibi debilisque lingua est, nobis filia fortius loquetur: tam dispar aquilae columba non est nec dorcas rigido fugax leoni.

Quare desine me uocare fratrem, ne te, Charmenion, uocem sororem ${ }^{33}$.

Antes de comentar este epigrama conviene que hagamos una pequeña digresión sobre la presencia de Hispania en la obra de Marcial y su orgullosa afirmación de identidad hispánica o celtibérica.

La crítica no ha dejado de ocuparse de estos temas desde el siglo pasado. Los estudiosos están de acuerdo en que Marcial, frente al silencio de otros escritores hispanos que triunfaron en la literatura romana ${ }^{34}$, le da una especial relevancia a su origen, aunque la mayoría sostiene que la identidad romana imperial predomina en su obra $^{35}$. De todas formas, Marcial inscribe en ella

33 Citamos por la edición de Fernández Valverde para Alma Mater, Madrid 2004-2005.

${ }_{34}$ Dolç 1987, p. 18; Arranz Sacristán 1987, p. 216 y Citroni 2003, pp. 282-286.

${ }^{35}$ Una excepción a esto se encuentra en los dos estudiosos españoles citados, porque elevan la identidad española de Marcial hasta igualarla con la romana y destacan su papel en la construcción de una identidad nacional española, más allá del carácter celtibérico que se atribuye con frecuencia a sí mismo (Dolç 1987, pp. 15-18 y Arranz Sacristán 1987, pp. 220221). Frente a ellos Citroni 2003, pp. 287-288, hace un recuento de los epigramas sobre el tema y solo encuentra en la extensa obra de Marcial 60 epigramas en los que habla de ciudades, ríos y lugares hispanos, 31 en los que nombra a personajes hispanos y 23 con referencias a sí mismo como hispano o celtibérico. 
desde el principio (I 49 y I 61) a Hispania como lugar de la memoria, convierte su espacio, sus lugares (IV 55) y sus hombres (especialmente sus poetas y escritores) en tema poético, que aparece de vez en cuando a lo largo de sus libros; y finalmente, cuando las circunstancias políticas en Roma cambian y su posición en la ciudad se vuelve más precaria, en el libro X decide volver a Bílbilis y subraya su identidad hispánica ${ }^{36}$, aunque al final del libro formule la sospecha de que en la provincia echará de menos a Roma (X 103). Este presagio se verá confirmado en los epigramas del libro XII, que desmontan la imagen idílica de Hispania, construida desde la distancia: la tranquilidad de Bílbilis conlleva también la mezquindad y la envidia de los provincianos y no compensa la pérdida de la palpitante vida de la Vrbs que había nutrido su obra, con sus termas, cenas, teatros, lugares de encuentro y hombres de todos los lugares del Imperio. Señala Citroni 2003, pp. 292-293, que su reivindicación como español no se extiende a su actividad como poeta y que no propone su obra como producto de una cultura provincial, sino como una realización enteramente romana. La identidad hispánica de Marcial solo se define por sus rasgos étnicos: carácter, temperamento, aspecto físico, etc. Esta diferenciación es interesante porque nos ayuda a explicar mejor la contradicción entre la tolerancia con los otros, señalada antes, y la xenofobia que desde su identidad hispánica muestra en este epigrama.

Roma, como lugar de inspiración de su poesía y centro del poder imperial con el que el poeta se compromete, lo dota de una identidad que no favorece, como hemos dicho, los ataques xenófobos, porque, si lo pensamos bien, el Imperio romano era ya difícilmente identificable con una nación, dada su dimensión universal ${ }^{37}$; de manera que apenas podía alimentar la xenofobia tan unida al nacionalismo. Pero ningún imperio ha conseguido nunca borrar por completo las fronteras ni eliminar los sentimientos nacionalistas de los individuos, que permanecen unidos a su patria chica. Por eso Marcial en este

36 Dice Fearnley 2003, pp. 618-629, que en el libro X el epigramista cambia de Marcial como romano a Marcial como hispanus, que se aparta de los temas políticos para concentrarse en el repaso de su vida, de la pasada y de sus planes de futuro. El silencio sobre la política lo interpreta esta autora como un rechazo de la ideología imperial de la ciudad, de la que ha sido comentarista en sus libros previos.

${ }^{37}$ Como señala Barchiesi 2005, p. 399, la confusión del Imperio romano con una nación se debe a que desde las culturas nacionales en las que se implantó el estudio de los clásicos se llevó a cabo una asimilación más o menos sutil del pasado romano a su presente, una asimilación que debemos evitar. 
único desahogo explícito contra un griego lo ataca desde su identidad celtibérica.

La contraposición entre el poeta, que se identifica como celtibérico (3-4) e hispano (7) y Carmenión, un griego de Corinto (1), se basa en su apariencia y rasgos físicos: a los cuidados cabellos del griego (flexa...coma, 6), el poeta opone su indomable pelambrera hispánica (Hispanis ego contumax capillis, 7); a la suavidad que la depilación cotidiana le presta a la piel del corintio (8), el poeta opone sus mejillas y miembros hirsutos (9) y, finalmente, la voz del griego es delicada y suave (10), mientras que entre los celtíberos hasta las jovencitas la tienen «más fuerte» (11). El epigramista subraya también la distancia por medio de una cuidadosa elección del vocabulario: para los cabellos del corintio el poético coma, para los suyos el prosaico capellis, como corresponde al artificio del uno frente a la naturalidad del otro, contraposición señalada también por os blaesum, la voz balbuciente adoptada por el primero para acentuar la suavidad de su carácter (mollis).

La descripción de los rasgos diferentes de cada uno es económica; pero adquiere todo su sentido en el contexto. La comparación que lleva a cabo el poeta está motivada porque Carmenión le ha llamado frater (v 3). El epigramista lo toma en sentido literal, por desplazamiento, de manera que puede señalar las diferencias entre los dos «hermanos» (an uoltu similes uidemur esse? 5) y preparar el chiste final ${ }^{38}$ : Quare desine me uocare fratem, /ne te, Charmenion, uocem sororem. De esta forma, la confrontación entre las apariencias de ambos sirve para contraponer la virilidad del poeta a la blandenguería del corintio, caracterizado como un pathicus, que se le insinúa y es rechazado por é $1^{39}$. Una vez más el ataque se apoya en el rasgo del estereotipo romano de los griegos más apropiado para la lasciuia del epigrama: su afeminamiento. Además el hecho de que esté limitado a un único vicio y la agudeza del chiste lo mantienen muy lejos de la ferocidad y el sarcasmo del ataque juvenaliano.

No es de extrañar que este epigrama, el único en el que se satiriza explícitamente a un griego como tal, aparezca en el libro X, el libro en el que

38 «Chistes por desplazamiento» les llamó Freud 1973, p. 15, a los que se producen por «una desviación del proceso mental, el desplazamiento psíquico sobre un tema distinto del iniciado».

${ }^{39}$ Cf. Obermayer 1998, p. 247, sobre el uso de estos términos en Marcial para señalar esta contraposición. 
Marcial se distancia de Roma, a la que empieza a ver como lugar de exilio, oscuro y peligroso, mientras prepara su vuelta a la «augusta» Bílbilis ${ }^{40}$, que representa en parte como una Roma nueva, un lugar ideal perdido y a punto de ser recuperado ${ }^{41}$. Por eso quizás la rusticitas con la que se autorretrata se parece a la que atribuye en otros epigramas a los campeones de la antigua uirtus romana: los Curios y Camilos, pilosi (IX 27, 6-7) o capillis incomptis (I 24), a los que imitan los pathici que quieren ocultar sus inclinaciones sexuales. Esta coincidencia ha sido interpretada como una afirmación más de la romanitas de Marcial, con una especie de desplazamiento hacia el oeste del imperio de las virtudes primitivas de Roma ${ }^{42}$; pero no tenemos que perder de vista que la rusticitas y simplicitas, convencionales y propias de pueblos primitivos e incontaminados por la civilización, se las atribuye el poeta a sí mismo como celtibérico, y que en su tiempo eran más creíbles, sin duda, en un municeps de Bílbilis, por romanizada que esta estuviera, que en un vecino de Roma. Además, a la descripción de su salvaje vellosidad le añade un rasgo peculiar de los hispanos (Citroni 2003, p. 287): el oscuro y rudo acento que algunos autores latinos criticaban ${ }^{43}$. De modo que, aunque recurra a los términos habitualmente utilizados en la literatura latina para describir a los grandes campeones de la virtud romana, el ataque contra Carmenión lo lanza como hispano celtibérico recio, que afirma su virilidad frente al griego afeminado.

Ahora bien, dado que la disposición de los poemas en el libro le permitía a Marcial superar el carácter conciso y fragmentario del género recurriendo a la yuxtaposición de epigramas complementarios por semejanza u oposi-

${ }^{40}$ Tras la pacificación de Hispania por Augusto, Bílbilis alcanzó el estatus de municipium y recibió el título de Augusta, una posible indicación de la temprana colaboración de la ciudad con los romanos (Sullivan 1991, p. 174).

${ }^{41}$ Sobre el valor moral que el paisaje de Bílbilis toma a veces en Marcial cf. Bonjour 1975, pp. 255-56.

42 Esta semejanza lleva a Notter (2011, pp. 181-189) a negar que aquí tengamos a un auténtico celtíbero y a sostener que se trata de un retrato convencional de viejo romano, encarnado ahora no sin ironía en un provincial de raza bárbara. Para esta autora la identidad hispánica de Marcial es pura construcción poética y literaria sin apoyo en ningún sentimiento patriótico o étnico, frente a la expresión masiva en su obra de su identidad romana.

${ }^{43}$ En Pro Archia 26 se refiere Cicerón al acento de los poetas de Córdoba pingue quiddam atque peregrinum y Séneca el Viejo en la semblanza de Porcio Latrón que nos ofrece en Con. I Praef. 16 dice: Vox robusta, sed surda...Nulla umquam illi cura uocis exercendae fuit; illum fortem et agrestem et Hispaniae consuetudinis morem non poterat dediscere. 
ción $^{44}$, vamos a examinar el contexto en el que X 65 aparece para ver si Marcial matiza la persona adoptada en él.

En efecto en X 66 encontramos una corrección a la rudeza celtibérica del epigrama anterior. En él lamenta que un bello Ganímedes haya sido relegado a la cocina con el consiguiente peligro para su belleza. Su punto de vista ahora es el de un romano civilizado, sensible a la belleza de un joven. Esto no significa que se aproxime ahora al griego del epigrama anterior, pues en toda la secuencia de temática sexual, compuesta por los epigramas X 64-X 69, el epigramista mantiene la actitud normativa del uir romanus adulto que siempre desempeña el papel activo en las relaciones sexuales ${ }^{45}$.

La secuencia está compuesta por tres epigramas, que de alguna forma pueden relacionarse por la presencia mayor o menor en ellos de la temática homoerótica (X 64-X 66), y otros tres de ataque misógino a mujeres sexualmente activas y dominantes (X 67-X 69). La abre un epigrama dirigido a Pola Argentaria ${ }^{46}$, la viuda de Lucano, en el que le pide que no sea severa con la lasciuia de su poesía porque su marido también escribió algún verso lascivo, en el que incluso se manifestaba como pathicus: «Si nec pedicor, Cotta, quid hic facio?». El último, X 69, va dirigido a una mujer, curiosamente llamada también Pola, que invierte los papeles y pone a su marido en el papel de esposa. Esta Pola es un personaje ficticio que no tiene nada que ver con la del X 64; pero la aparición del mismo nombre femenino en el epigrama que

${ }^{44}$ Como dice Marcial en VII 85, 3-4 Facile est epigrammata belle/ scribere, sed librum scribere difficile est. La disposición de los epigramas dentro del libro ha sido objeto de numerosas investigaciones y algunos estudiosos han identificado ciclos de epigramas relacionados por motivos o protagonistas (Barwick 1958) o diversos modelos de agrupación por tipos o temas (Scherf 2001). Otros han descubierto modos de ordenación más flexibles (series sobre un mismo tema, Merli 1998) o han intentado elucidar modelos más complejos y amplios (Garthwaite 1998), porque el «antiorganicist mode» del libro de epigramas se resiste a entrar en modelos estrictos. Preferimos por eso hablar de epigramas yuxtapuestos en secuencias y relacionados sin rigidez por el tema. Rimell 2008, pp. 20-50, por su parte, ve la concepción del libro I como una metáfora de la mezcla social de la Roma flavia y señala que Marcial se muestra «as an aggresive innovator experimenting in a radical way with the chemistry of interconnection, and with the contradiction of jumbled order» (p. 50).

45 Cf. Sullivan 1991, pp. 185-210, Richlin 1992, p. 140 y Montero Cartelle 2004, pp. 135-140.

46 Fue mecenas del poeta al principio de su estancia en Roma, por eso se dirige a ella como regina en X 64,1. A un encargo suyo para celebrar el aniversario de su marido se deben los epigramas VII 21-VII 23 (Nauta 2002, p. 225). 
cierra la secuencia, y el hecho de que ponga a su marido en la posición subordinada de una mujer, como un pathicus, nos permite pensar en una secuencia buscada, aunque como dice Fitzgerald (2007, pp. 4-7) el establecimiento de tales secuencias produce con frecuencia incertidumbres en la interpretación.

De todas formas la posibilidad de secuencia buscada por el poeta se ve fortalecida porque en el centro de la segunda tríada encontramos un epigrama (X 68), que se corresponde temáticamente con X 65 en posición central en la primera, ya que critica la grecomanía de una mujer, que a pesar de ser romana de vieja cepa (3-4), adopta costumbres griegas poco recomendables:

Cum tibi non Ephesos nec sit Rhodos aut Mitylene, sed domus in uico, Laelia, Patricio, deque coloratis numquam lita mater Etruscis, durus Aricina de regione pater

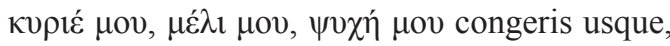
pro pudor! Hersiliae ciuis et Egeriae.

Lectulus has uoces, nec lectulus audiat omnis, sed quem lasciuo strauit amica uiro.

Scire cupis quo casta modo matrona loquaris? numquid, cum crisas, blandior esse potes?

Tu licet ediscas totam referasque Corinthon, non tamen omnino, Laelia, Lais eris.

La evocación de Hersilia, la esposa de Rómulo, y Egeria, la ninfa que le inspiró al rey Numa la religión romana, sirve para recordarle a Lelia la norma tradicional de conducta sexual de una noble matrona, de la que ella se aparta, porque, además de traicionar la romanitas utilizando expresiones griegas, falta al decorum ya que tales expresiones solo son propias de los encuentros sexuales con un amante (cf. lasciuo strauit amica uiro, 8). Su forma de hablar recuerda a Lais una bella y famosa prostituta corintia, maestra en el arte de la seducción.

Esta referencia a Corinto estrecha la relación de este epigrama con el de Carmenión; pero la víctima del ataque no es ahora un griego sino una mujer romana, una matrona contaminada por las costumbres griegas. También Juvenal, en VI 184-199, lanza el mismo tipo de censura contra todas las romanas, que no se consideran hermosas, nisi quae de Tusca Graecula facta est 
(186), que expresan todas sus emociones en griego y concumbunt Graece (191) y seducen con blandas y acariciadoras palabras griegas. La diferencia de nuevo se produce entre la amplificatio del vicio que permitía la sátira y el impulso que le daba la ira del satírico, y el alcance personal y ocasional del epigrama, que, sin carecer de maliciosa misoginia, concentra su efecto en la insinuación final de que nunca Lelia podrá convertirse en una mujer tan atractiva como Lais (Watson \&Watson 2003, p. 229). Como en X 65 tenemos de nuevo un «chiste por desplazamiento»: deja a un lado las consideraciones de tipo social y moral y pone el acento en las condiciones físicas de la mujer para triunfar en el terreno sexual; de manera que en cierta forma frivoliza la censura.

La situación en el centro de cada tríada de los dos epigramas lanzados contra las costumbres helénicas destaca la relación entre ellos y los refuerza, aunque, como hemos visto, el chiste del epigrama aligere su crítica. Ni siquiera la adopción de la persona dura de hispanus, y la perspectiva de la vida rural de Bílbilis, alcanzan a darle a la xenofobia de Marcial hacia los griegos y sus costumbres la contundencia de la de Juvenal y eso que los dos coinciden en la idea de buscar descanso en su tierra natal: también el satírico en III 317-322 hace que Umbricio se refiera a sus escapadas a Aquino para descansar del ajetreo de la vida en Roma ${ }^{47}$. Pero Marcial, a diferencia de Juvenal no proyecta desde su nacionalismo celtibérico miedo en relación con los griegos. La distancia y la crítica de Marcial no son defensivas y por eso son menos punitivas. Al final tenemos que concluir que incluso adoptando una actitud nacionalista, Marcial no se siente amenazado por los griegos ni teme que Carmenión o Lelia se conviertan en modelos de conducta para los vecinos de la apacible Bílbilis.

De modo que resumamos para terminar las conclusiones a las que hemos llegado sobre la visión de Marcial de los griegos. En primer lugar, su visión, frente a la de Juvenal, presenta ambivalencias, porque admite la vertiente tradicional positiva de admirar la cultura y la literatura griegas. En segundo lugar y, sobre todo, al sentirse ciudadano de un imperio multicultural, adopta un punto de vista totalmente contrapuesto al del satírico: frente a Juvenal, para él la romanitas no es ya cuestión de una natio, identificada con Roma/

${ }^{47}$ Merli 2006, pp. 338-345, ve la retirada de Marcial a Bílbilis, no tanto como la búsqueda del campo en contraposición a la ciudad, sino como una opción que se había hecho común en la clase alta romana, el campo como lugar de retirada a determinada edad. 
Italia, sino del mundo entero dominado y colonizado por Roma, en el que, aunque persistan las fronteras y las diferencias lingüísticas y culturales, la mayoría son ciudadanos romanos y, sobre todo, lectores potenciales garantes de la fama y la inmortalidad del poeta. No cabían ataques xenófobos furibundos contra ellos, como el que Juvenal lleva a cabo desde su estrecho y rancio nacionalismo romano. Frente a él la presencia de helenofobia en la obra de Marcial queda reducida a la exposición irónica de la helenofilia de algunos poetas y mujeres romanas, a ataques individuales contra algunos griegos particulares identificados como tales por sus nombres y al epigrama contra el corintio Carmenión, el único caso en el que se ataca a un griego como griego y no como persona. Además solo se le ataca por ser pathicus, pasivo en las relaciones homoeróticas. La selección de este vicio entre los que presentaba el estereotipo romano de los griegos está determinada por la lasciuia característica del epigrama, que era una de las fuentes principales del entretenimiento que este género literario intentaba proporcionar a sus lectores. De modo que, si bien no se pueden negar puntos de contacto entre los dos poetas, en lo que se refiere a la visión de los griegos se encuentran entre ellos sobre todo diferencias insalvables debido a las perspectivas tan distintas desde las que ambos miraron a los «otros».

\section{BiBLIOGRAFÍA}

Adams, J. N. 2003: «Romanitas and latin language», ClQ 53, 184-205.

Alcock, S. E. 1993: Graecia capta. The landscapes of Roman Greece, Cambridge.

Arranz Sacristán, F. 1987: «Hispania vista por Marco Valerio Marcial» en Actas del simposio sobre Marco Valerio Marcial, poeta de Bílbilis y de Roma (Calatayud, Mayo 1986), Zaragoza, vol. II, pp. 215-236.

Barchiesi, A. 2005: «Centre and Periphery», en Harrison, S. (ed.), A companion to latin literature, Oxford, pp. 394-405.

Barwick, K. 1958: «Zyklen bei Martial und in der kleinen Gedichten des Catull», Philologus 102, pp. 284-318.

Beltrán, J. A. 2005: «Fuentes y modelos» en Beltrán, José A.; Encuentra, Alfredo P.; Fontana, Gonzalo G.; Iso, J. Javier; Magallón, Ana y Marina, Rosa Ma (eds.), Marco Valerio Marcial: Actualización científica y bibliográfica. Tres décadas de Estudios sobre Marcial (1971-2000), Zaragoza.

Bonjour, M. 1975: Terre natale. Études sur une composante affective du patriotisme romain, Paris. 
Citroni, M. 1975: M. Valerii Martialis Epigrammaton Liber I, a cura di.... Introduzione, testo, apparato critico e commento, Florencia.

Citroni, M. 2002: «L'immagine della Spagna e l'autorappresentazione del poeta negli Epigrammi di Marziale», en Urso, G. (ed.), Hispania terris omnibus felicior. Premesse ed esiti d'un processo di integrazione (Atti del convengo internazionale Cividade del Friuli, 27-29 settembre 2001), pp. 281-301.

Citroni, M. 2004: «Martial, Pline le jeune et l'identité du genre de l'epigramme latine», Dictynna 1, mis en ligne le 15 novembre 2010. URL: http://dictynna. revues.org/172. (20/01/2011).

Cizek, E. 1989: «L'image de l'autre et les mentalités romaines du Ier au IV siècle de nostre ère», Latomus 48, pp. 360-371.

Coleman, K. 2006: M. Valerii Martialis Liber Spectaculorum, Oxford.

Colton, R. E. 1991: Juvenal's use of Martial's epigrams: a study of literay influence, Amsterdam.

Cortés Tovar, R. 2007: Juvenal. Sátiras. Edición bilingüe con Introducción y notas. Madrid.

Dolç, M. 1987: «Marcial, entre Roma y Bíbilis» en Actas del simposio sobre Marco Valerio Marcial, poeta de Bílbilis y de Roma (Calatayud, Mayo 1986), Zaragoza, vol. II, pp. 11-22.

Dubuisson, M. 1991: «Graecus, graeculus, Graecari: l'emploi pejoratif du nom des

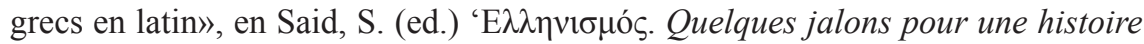
de l'identité grecque. Actes du Colloque de Strasbourg, 25-27 d'octobre 1989, Leiden-Nueva York, Kobenhaun, Colonia, pp. 315-335.

Fearnley, H. 2003: «Reading the imperial Revolution: Martial Epigrams 10» en Boyle, A. J. \& Dominik, W. J., Flavian Rome: Culture, Image, Text. LeidenBoston, pp. 611-635.

Fitzgerald, W. 2007: Martial. The World of the Epigram, Chicago, Londres.

Freud, S. 1973: El chiste y su relación con lo inconsciente, Madrid (3a ed. en castellano).

Galán Vioque, G. 2002: Martial, Book VII. A commentary. Translated by Zoltowsky, J. J., Leiden-Boston-Colonia.

Garthwaite, J. 1998: «Patronage and poetic Immortality in Martial, Book 9», Mnemosyne 51, pp. 161-175.

Gunderson, E. 2003: «The Flavian Amphitheatre: All the World as Stage» en Boyle, A. J. \& Dominik, W. J. (eds.), Flavian Rome: Culture, Image, Text. LeidenBoston, pp. 637-658.

Isaac, B. 2004: The invention of racism in Classical Antiquity, Princeton and Oxford.

Knight, CH. A. 2004: The Literature of Satire, Cambridge.

Laurens, P. 1989: L'abeille dans l'ambre: célébration de l'epigramme de l'époque alexandrine à la fin de la Renaissance, Paris. 
Leâo, D. F. 2004: «Zoilo e Trimalchiâo. Duas variaçoês sobre o tema do novo-rico» en Sousa Pimentel, C. de; Leâo, D. F.; Brandâo, J. L. L. (coord.), Totus notus in orbe Martialis. Celebraçâo de Marcial 1900 anos após a sua morte, CoimbraLisboa, pp. 191-208.

Malnati, T.P. 1988: «Juvenal and Martial on social mobility», $C J$ 83, pp. 133-141.

Mattiacci, S. 2007: Anti-mitologia ed eredità neoterica in Marziale: genesi e forme di una poetica, Ospedaletto.

Merli, E. 1998: «Epigrammzyklen und 'serielle Lektüre' in den Büchern Martials. Überlegungen und Beispiele» en Grewing, F. (hg.), «Toto notus in orbe». Perspektiven der Martial-Interpretation, Stuttgart, 139-156.

Merli, E. 2006: «Martial betwen Rome and Bilbilis», en Rosen, R. M.; Sluiter, I. (ed.), City, countryside and the spacial organisation of value in Classical Antiquity, Leiden-Boston (Mnemosyne Suppl. 279), pp. 327-347, 2006.

Montero Cartelle, E. 2004: «Marcial, ¿erótico?», en Iso Echegoyen, J.J. y Encuentra, A. (eds.), Hominem pagina nostra sapit, Marcial 1900 años después, Zaragoza, pp. 129-149.

Moreno Soldevila, R. 2006: Martial, Book IV: a commentary, Leiden-Boston.

Nauta, R. R. 2002: Poetry for patrons. Literary communication in the Age of Domitian, Leiden-Boston-Colonia.

Notter, C. 2011: «Identité romaine et identité espagnole chez Martial» en Simon, M. (ed.), Identités romaines, conscience de soi et representations de l'autre dans la Rome antique, París, 177-190.

Obermayer, H. P. 1998: Martial und der Diskurs über männliche «Homosexualität» in der Literatur der früen Kaiserzeit, Tubinga.

Puelma, M. 1997: «Epigramma: osservazioni sulla storia di un termine greco-latino», Maia 49 pp. 189-213.

Richlin, A. 1992: The Garden of Priapus. Sexuality \& Aggression in Roman Humor, Nueva York-Oxford.

Rimell, V. 2008: Martial's Rome. empire and the ideology of epigram, Cambridge.

Scherf, J. 2001: Untersuchungen zur Buchgestaltung Martials, Stuttgart.

Sherwin-White, A. N. 1970: Racial prejudice in imperial Rome, Cambridge.

Shumate, N. 2006: Nation, empire, decline. Studies in rhetorical continuity from the Romans to the modern era, Londres.

Socas, F. 1995: «Graeculus esuriens: la actitud de Juvenal ante los griegos» en Falque, E. y Gascó, F. (eds.), Graecia capta. De la conquista de Grecia a la helenización de Roma, Huelva, pp. 149-170.

Socas, F. 2006: «Marcial y los extranjeros», Habis 37, pp. 333-347.

Sullivan, J. P. 1991: Martial. The unexpected classic, Cambridge.

Syed, Y. 2005: «Roman and Others», en Harrison, S. (ed.), A companion to latin literature, Oxford, pp. 360-371. 
Vallat, D. 2008: Onomastique, culture et societé dans les Épigrammes de Martial, Bruselas.

Watson, L. \& Watson, 2003: Martial. Select epigrams, Cambridge.

Williams, C. A. 2002: «Sit nequior omnibus libellis. Text, Poet, and Reader in the Epigrams of Martial», Philologus 146, pp. 150-171.

Williams, C. A. 2004: Epigrams. Book two /Martial; ed. whith introduction, translation and commentary, Oxford.

Fecha de recepción de la primera versión del artículo: 31/07/2012

Fecha de aceptación: 07/03/2013

Fecha de recepción de la versión definitiva: 14/03/2013 